\title{
Anthrax case provokes doubt among experts
}

Jonathan Knight and Erika Check

In the FBI's search for whoever mailed anthrax to various US targets last autumn, both the hunter and the hunted are working hard to marshal facts in their favour. In so doing, both have released information of questionable scientific merit, experts say, perhaps shedding more heat than light on the continuing investigation.

Steven Hatfill, a former biodefence researcher at the US Army Medical Research Institute of Infectious Diseases at Fort Detrick in Frederick, Maryland, has been the subject of a barrage of media reports linking him to the case although the FBI says that he is not officially a suspect. Newsweek magazine reported on 12 August that bloodhounds had "jumped and barked, indicating they'd picked up the scent" when investigators led them to Hatfill's girlfriend's apartment and a restaurant where he had eaten the day before.

This information could only have come from law-enforcement sources. But bloodhound experts poured cold water on the idea that such a response would reliably reflect the dogs' recognition of a scent taken from packages that had each been handled by many different people almost a year ago.

\section{Public plea}

Hatfill, meanwhile, publicly pleaded his innocence by claiming, among other things, that as a virologist he wouldn't have known how to handle anthrax, which is a bacterium. Hatfill made the claim during a 15-minute public statement on 11 August in which he bitterly complained that FBI and media scrutiny had made a "wasteland" of his life.

"I have never, ever worked with anthrax in my life," Hatfill said. "It's a separate field from the research I was performing at Fort Detrick." Hatfill's civil lawyer, Victor Glasberg, then emphasized the point by suggesting that "not too many people doing the investigation understand the difference between a virus and a bacterium".

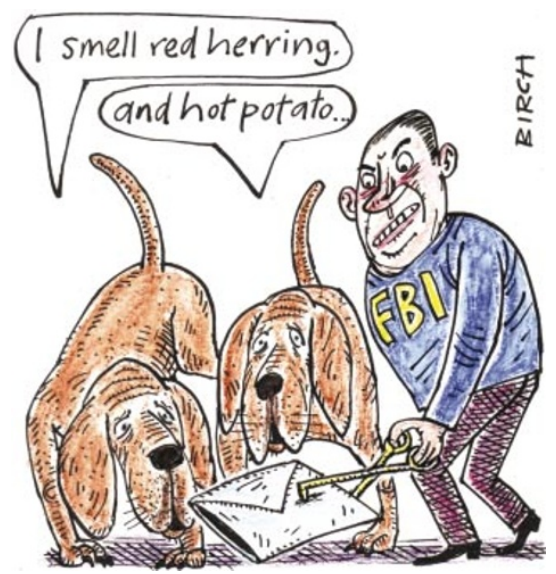

But microbiologists and bioweapons experts say that the distinction between the skill sets required to work with the two types of bioweapon agents is a difficult one to draw. Although the methods involved in growing viral and bacterial agents and using them in weapons differ in important ways, the overlap is considerable, they point out.

As obligate parasites, viruses can only be grown in host cells. Researchers who work with Ebola virus and monkeypox, as Hatfill did at Fort Detrick from 1997 to 1999, culture mammalian cells and infect them with the viral agent.

By contrast, the anthrax bacterium, Bacillus anthracis, is easier to grow than most viruses, requiring only nutritive broth or agar plates. The only technical part involves coaxing it to form spores, the dehydrationtolerant form used in last autumn's mailings. But this would pose little problem for a competent virologist, says Mark Wheelis, a microbiologist and arms-control expert at the University of California, Davis.

Other tricks are required to turn bioweapons agents into fine powders, or aerosols, that can be inhaled, and these vary from agent to agent. Viruses, for example, must be treated with chemicals to stop them falling apart when dried. But the steps to making an aerosol of any agent share several critical elements. Cultures are sprayed into fine particles and then dried, or first dried and then milled.

Emphasizing the differences between organisms merely sidesteps the more crucial question of access, says Al Zelicoff, a bioweapons expert at Sandia National Laboratories in New Mexico. "The real issue here is how someone got hold of a large amount of aerosolizable anthrax," he says.

\section{On the scent}

Criminologists, meanwhile, are scratching their heads over the bloodhound claims that appeared in the press. Several experts contacted by Nature say that the anthrax letters were unlikely to yield an ideal scent sample. Jerry Nichols, president of the Law Enforcement Bloodhound Association, says that scent from a letter could be used months later only if it had been lifted immediately and properly sealed. Nichols adds that he knows of cases in which courts "overturned or would not allow such evidence because there were too many questions of possible contamination". The FBI has declined to comment on the bloodhound incident or on how the scent was obtained.

Research has produced conflicting claims about bloodhounds' reliability. The most encouraging results suggest that they can correctly identify a suspect out of a line-up around $85 \%$ of the time. But one study found

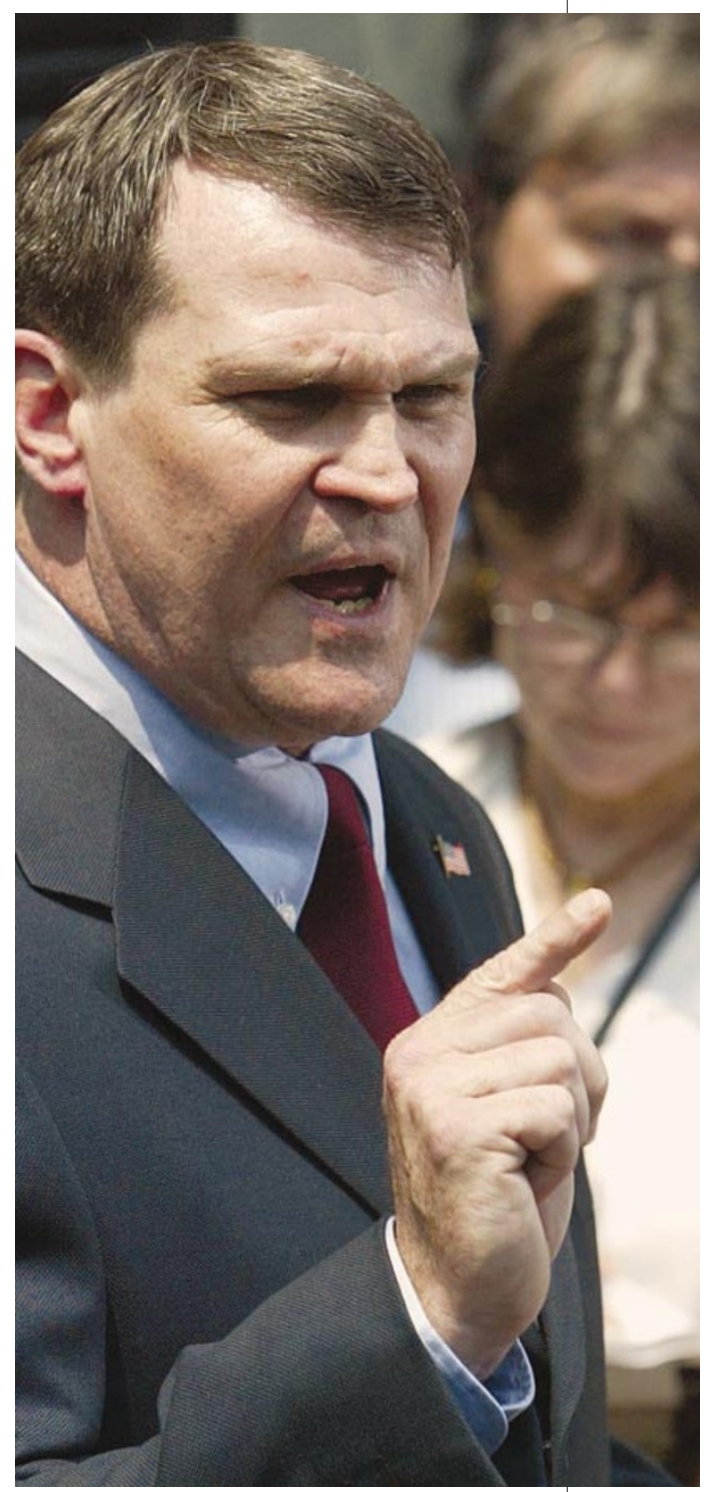

Not in the know: Steven Hatfill says that he lacks the expertise to unleash an anthrax attack.

that when the person whose scent was taken is omitted from a line-up, dogs choose someone at random almost half the time anyway.

"It's not that dogs can't do a scent match," says Larry Myers, a veterinarian who researches canine scent tracking at Auburn University's College of Veterinary Medicine in Alabama. "But we don't know how well they do it. There simply haven't been enough studies."

Nichols and others say that dogs can also respond to unintentional signals from their handlers, who should therefore not be told about where the dogs are expected to react. But as the anthrax investigation drags on, the chances of a thorough double-blind study being done on this or any other technical issues raised seem to be remote. 